\title{
Assessment of Nursing Practice Regarding Neonates with Hyperbilirubinemia
}

\author{
Amna A. Ramdan ${ }^{1}$, Nafisa H. Refat ${ }^{2}$ \& Amal A. Mobarak ${ }^{3}$. \\ Clinical Nursing Specialist, Children Hospital, Assuit University, Egypt. \\ Professor of Pediatrics , Faculty of Medicine, Assuit University, Egypt. \\ Assistant Professor of Pediatric Nursing, Faculty of Nursing, Assuit University, Egypt.
}

\begin{abstract}
There is no doubt that hyperbilirubinemia is one of the most common diagnoses in the neonatal period; it is estimated to occur in $60 \%$ of term newborns in the first week of life. Aim: This study aimed to assess nursing practice regarding neonates with hyperbilirubinemia. Design: Descriptive research design was used to conduct this study. Subjects and method: A convenience sampling of 40 nurses caring for neonates with jaundice who admitted to neonatal intensive care unit of Assuit University Children Hospital. Setting: This study was conducted at Neonatal Intensive Care Unit of Assuit University Children Hospital. Tools: Two tools were used to collect the necessary data, a maternal \& neonatal personal data sheet and observation checklist sheet. Results: It was found that all of the studied nurses $(100 \%)$ had satisfactory level of practice related to weight, and one quarter $(25 \%)$ of them had satisfactory level of practice related to skin care, while only $(2.5 \%)$ had unsatisfactory level of eye care, diaper care and gavage feeding and there was no statistical significant relation between nurses level of practice, and their marital status, residence, age, years of experience and educational level. Conclusion: There were no statistically significant relationship between nurses' level of practice and their personal characteristics. Recommendations: Provideing nurses with procedure manual hand books containing all necessary information about nursing procedures related to quality of nursing care for neonates with hyperbilirubinemia will be benficial.
\end{abstract}

\section{Keywords: Hyperbilirubinemia, Neonate, Nurses \& Practice.}

\section{Introduction}

Hyperbilirubinemia refers to an excessive level of accumulated bilirubin in the blood and is characterized by jaundice, or icterus, a yellowish discoloration of the skin and other organs.. Jaundice is present in most newborns and is usually benign (Wong's, 2015 \& Renesme \& et al., 2016). It affects $60 \%$ of the full-term infants and $80 \%$ of premature infants in the first three days after birth. It is also considered the factor that increase the likelihood in contracting jaundice are low income, hospital setting, and genetics. In addition, persons of African, Mediterranean, Middle Eastern, or Southeast Asian descent are more likely to contract jaundice (HennyHarry \& Trotman, 2012 \& Gurley et al., 2012).

Unconjugated (indirect) hyperbilirubinemia occurs as a result of excessive bilirubin formation and because the neonatal liver cannot clear bilirubin rapidly enough from the blood. (Maisels et al., 2014 \& Norman et al., 2015). Physiological jaundice is a normal process seen in $45-60 \%$ of term newborns during the first few days of life. Pathological jaundice arises from factors which alter the usual processes involved in bilirubin metabolism. Hyperbilirubinaemia needing treatment may arise from physiological or pathological causes. Jaundice appearing within 24 hours of birth or after 14 days is considered to be outside the normal process and pathologic. (Edris et al., 2014).

The most obvious sign of hyperbilirubinemia is jaundice, the yellowish discoloration primarily of the sclera, nails and skin. Jaundice that appear within 24 hours is caused by hemolytic disease of the newborn. Jaundice that appears on the second or third day, peaks on the third to fourth day, and declines on the fifth to seventh day is usually aresult of physiologic jaundice. (Wong's, 2015)'

Although most newborns with jaundice are considered healthy, they need to be monitored because bilirubin is potentially toxic to the central nervous system. Sufficiently elevated levels of bilirubin can lead to bilirubin encephalopathy and subsequently kernicterus, with devastating, permanent neurodevelopmental handicaps. (AAP, 2011).

For preventing kernicterus and other complications of hyperbilirubinaemia, jaundice should be managed by phototherapy or Exchange Transfusion (ECT). (Olusanya et al., 2016).

Phototherapy is a useful method because it is easily available and devoid of all complications of double volume ECT. Despite ECT being an effective method in decreasing Total Serum Bilirubin (TSB) level after failing phototherapy, ECT remains an invasive procedure with associated morbidity and mortality. 
ECT should be considered only when the benefit of decreasing TSB level to prevent kernicterus outweighs the complications associated with the procedure. (Stokowski, 2011).

Phototherapy has been used since 1958 for the treatment of neonatal hyperbilirubinaemia. (Cremer, et al., 1958). It causes unconjugated bilirubin to be mobilised from the skin by structural isomerisation to a water soluble form (lumirubin) that can be excreted in the urine. (Macqueen et al., 2012). The aim of phototherapy is to decrease the level of unconjugated bilirubin in order to prevent acute bilirubin encephalopathy, hearing loss and kernicterus. (American Academy of Paediatrics, 2011)

Factors that influence the efficacy of phototherapy include: the light wavelength \& irradiance, bilirubin level, birth weight, gestational age, postnatal age, surface area exposed, skin thickness \& pigmentation and the etiology of the jaundice. (American Academy of Pediatrics, 2011). The distance between the light and neonate in intensive phototherapy is 15$20 \mathrm{~cm}$, while in traditional phototherapy is $35-50 \mathrm{~cm}$.

(Skinner, 2010).

Complications associated with phototherapy include loose stools, erythematous macular rash, purpuric rash associated with transient porphyrinemia, overheating, dehydration (increased insensible water loss, diarrhea), hypothermia from exposure, and a bengin condition called bronze baby syndrome (which occurs in the presence of direct hyperbilirubiemia). Because of the side effects of phototherapy a comprehensive plan of nursing care should be implemented to avoid any complications. (Kliegman, et al., 2011).

Once phototherapy has been initiated, frequent (every 6 to 12 hours) serum bilirubin levels are necessary because visual and transcutaneous assessments of jaundice are no longer considered valid, several precautions are instituted to protect the infant during phototherapy. The infant's eyes are shielded by an opaque mask to prevent exposure to the light. Eyes are checked at least every 4 to 6 hours for evidence of discharge, excessive pressure on the lids, or corneal irritation. Eye shields are removed during feedings, which provide the opportunity for visual and sensory stimulation. (Wong's, 2015).

The nurse plays an important role in caring of neonatal jaundice by continual reassessment and evaluation of neonates through, observing skin color, evaluating feeding, elimination pattern, checking placement of eye shields, skin for signs of dehydration, monitoring infant's temperature, interviewing family members and observing parentinfant interactions. (Wong's, 2015).

\section{Significance of the study}

Hyperbilirubinemia is a common and, in the most cases, benign problem in neonates. In Egypt severe neonatal hyperbilirubinemia accounted for $33 \%$ of total admissions to the neonatal intensive care units in 2010. Hyperbilirubinemia had a high flow rate in NICU in Assuit University Children Hospital, it was $20 \%$ in 2014 from totally admitted neonates. Which require not only immediate diagnosis and correction but also a continuous skilled nursing care of the neonates during the hospital stay to decrease the rate of morbidity, mortality, and cost. This study was designed to asses nursing practice regarding neonates with hyperbilirubinemia.

\section{Aim of the study}

This study aimed to asses nursing practice regarding neonates with hyperbilirubinemia.

Research questions

1- Do the nurses have a satisfactory level of practice regarding neonates with hyperbilirubinemia?

2- Are there a relation between nurses' level of practice and their personal characteristics?

\section{Subjects \& Method \\ Research Design}

Descriptive research design was utilized in this study.

Setting

This study was conducted at the Neonatal Intensive Care Unit of Assiut university children hospital which served the upper Egypt from El fayuom to Aswan.

Subjects

A convenience sampling of 40 nurses caring for neonates with jaundice who admitted to NICU of Assuit University Children Hospital.

\section{Tools of data collection:}

Two tools were used to collect the required data for this study:

Tool (I): Maternal and neonatal personal data sheet

Which was developed by the researcher and it included four parts:-

Part one: Personal data of the studied nurses: as (age, gender, marital status, educational level, residence, years of experience and attending related training program).

Part two: Maternal personal data: such as (age, education, occupation, residence, blood group , Rh and method of delivery (normal vaginal delivery or cesarean section). 
Part three: Neonatal personal data: such as (birth date, gender, gestational age, weight, type of feeding, date of admission and date of discharge)

Part four: Clinical data about the neonate's: such as (blood group and $\mathrm{Rh}$, clinical diagnosis, type of therapy, bilirubin \& hemoglobin level and vital signs).

Tool (II): Observation checklist sheet: The observation checklist sheet which was developed by the researcher based on related pediatric and critical nursing procedures manual to assess nurses, practice regarding neonates with jaundice and it included the following procedures: care of jaundiced neonates receiving phototherapy (13 steps), hand washing (12 steps) weighting (13 steps), vital signs (axillary temperature (13 steps), respiration (8 steps)), cord care (11 steps), eye care (15 steps), skin care (11 steps), diaper care (17 steps), bottle feeding (15 steps) and gavage feeding (17 steps).

Scoring system for practice

- A score of two grades was given for procedure done completely, one for done incompletely and zero for not done. There was 145 observation items total score for them 308 .

- For each part, the scores of the items were summed up and the total divided by number of the items giving a mean score for the part. These scores were converted in to a percent, mean and S.D were computed.

Total score of sub items =sum items

Satisfactory $\geq 65 \%$

Unsatisfactory $<65 \%$

Method of data collection

- An official permission was obtained from the director of NICU of Assuit University Children Hospital to collect the necessary data for this study. Content validity \& reliability

- Tool I \& Tool II were developed by the researcher and were tested for its contents validity by 5 experts in both pediatric nursing and and pediatrics fields and it was $95 \%$.

- The reliability of the tools was elicited by alpha Cronbach test and it was 0.82 for tool II.

\section{Pilot study}

A pilot study was carried out on $10 \%$ of nurses (4 nurses) to test the clarity and applicability of the sheet and to estimate time needed to fulfill each sheet. There was no modification done so, the nurses were included in the total sample of the study.

Field of the work

This study was carried out through a period of seven months from the beginning of April 2015 to the end of October 2015. The data collection done every day at NICU. Interviewing of studied nurses was conducted according to their available time in (morning, evening, and night shift) to collect data. Indirect observation for nursing practice regarding neonates with jaundice was done individually for each nurse. The time needed for observing each nurse ranged from 3-4 hours. Only one nurse observed per day.

\section{Ethical Consideration}

The ethical research consideration in this study include the following:

- Research proposal was approved from Ethical Committee in the Faculty of Nursing.

- There was no risk for study subjects during application of the research.

- The study followed common ethical principles in clinical research.

- Written consent was obtained from nurses that are willing to participate in the study, after explaining the nature and purpose the study.

- Nurses were assured that the data of this research will not be reused without second permission.

- Confidentiality and anonymity was assured.

- Nurses had the right to refuse participation and or withdraw from the study without any rational any time.

\section{Statistical analysis}

Data entry and data analysis were done using SPSS program (Statistical Package for Social Science) version 16. Data were presented as number, percentage, mean and standard deviation. P- value was considered significant when $\mathrm{p}<0.05$. 


\section{Results}

Table (1): Personal characteristics of the studied nurses ( $n=40)$.

\begin{tabular}{|c|c|c|}
\hline Nurses characteristics & $(n=40)$ & $\%$ \\
\hline \multicolumn{3}{|l|}{ Age in years: } \\
\hline • $20<30$ yrs. & 31 & 77.5 \\
\hline - $\quad 30<40 \mathrm{yrs}$ & 6 & 15.0 \\
\hline - $\quad \geq 40 \quad$ yrs. & 3 & 7.5 \\
\hline Mean+SD \& Range & \multicolumn{2}{|c|}{$28.8 \pm 5.6(21-42)$} \\
\hline \multicolumn{3}{|l|}{ Level of education: } \\
\hline - Secondary school of nursing. & 35 & 87.5 \\
\hline - Technical institute of nursing. & 5 & 12.5 \\
\hline \multicolumn{3}{|l|}{ Marital status: } \\
\hline • Married. & 33 & 82.5 \\
\hline - Single. & 7 & 17.5 \\
\hline
\end{tabular}

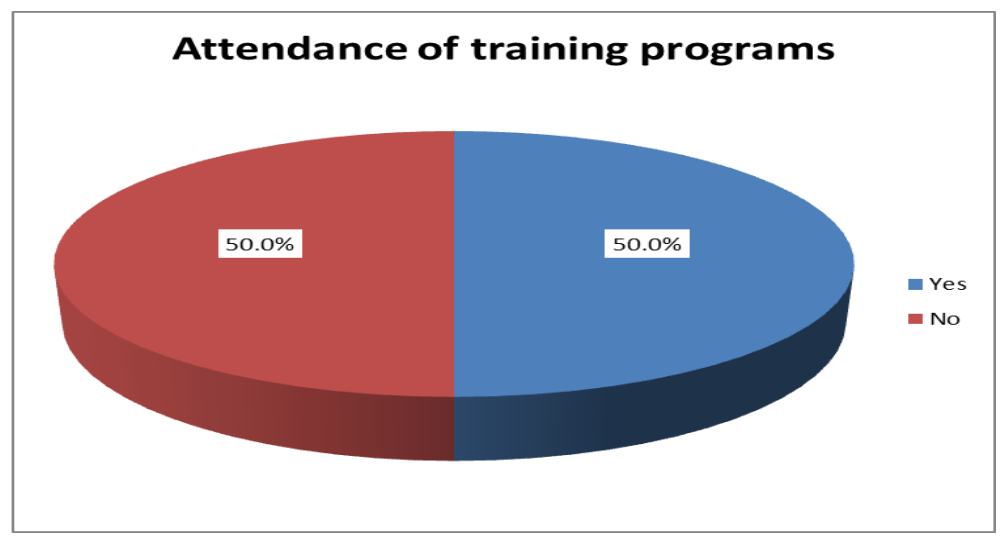

Figure (1): Distribution of the studied nurses according to their attendance of training programs

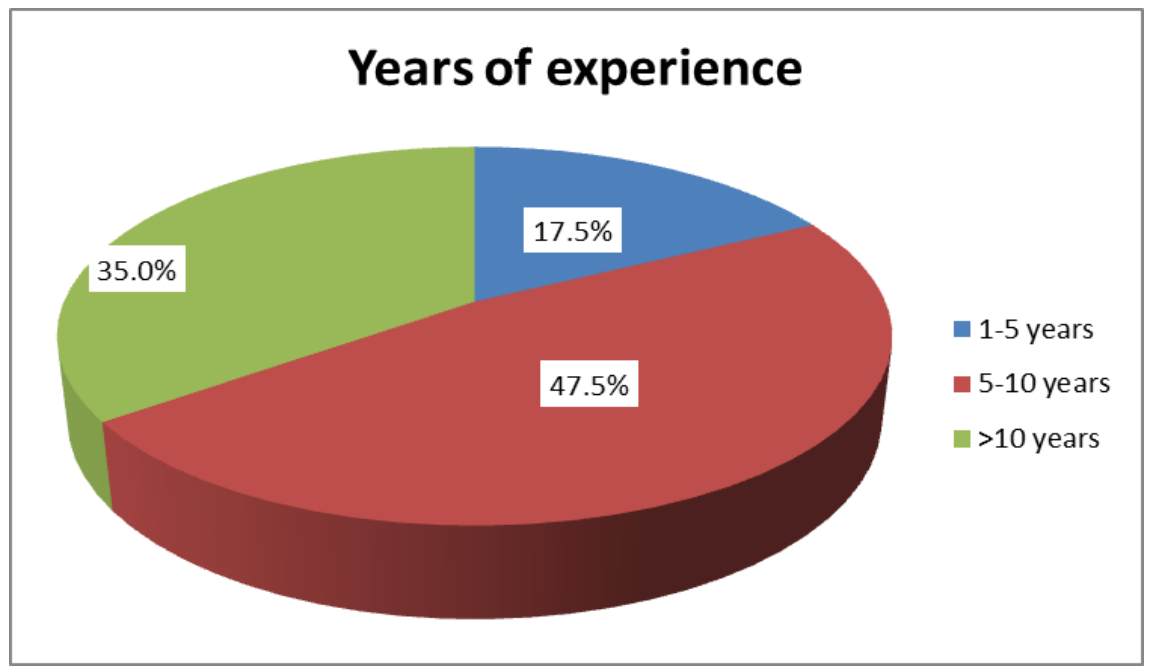

Figure (2): Distribution of the studied nurses according to their years of experience 
Table (2): Mean total score of the studied nurse's practice regarding caring of jaundiced neonates $(n=40)$.

\begin{tabular}{|l|c|c|c|c|c|c|}
\hline \multicolumn{1}{|c|}{ Procedures } & \multirow{2}{*}{$\begin{array}{c}\text { Total } \\
\text { score }\end{array}$} & \multirow{2}{*}{ Mean \pm SD } & \multicolumn{2}{|c|}{ Satisfactory } & \multicolumn{2}{c|}{ Unsatisfactory } \\
\cline { 4 - 7 } & & $\mathbf{n}$ & $\mathbf{\%}$ & $\mathbf{N}$ & $\mathbf{\%}$ \\
\hline - Care of infant receiving phototherapy & 26 & $19.6 \pm 1.8$ & 37 & 92.5 & 3 & 7.5 \\
\hline - Hand washing & 24 & $14.5 \pm 1.9$ & 13 & 32.5 & 27 & 67.5 \\
\hline - Weight & 26 & $20.1 \pm 1.2$ & 40 & 100.0 & 0 & 0.0 \\
\hline - Measuring body temperature (axillary) & 26 & $19.3 \pm 1.4$ & 38 & 95.0 & 2 & 5.0 \\
\hline - Measuring respiratory rate & 16 & $12.6 \pm 1.6$ & 33 & 82.5 & 7 & 17.5 \\
\hline - Cord Care & 22 & $17.6 \pm 2$ & 36 & 90.0 & 4 & 10.0 \\
\hline - Eye care & 30 & $23.5 \pm 1.9$ & 39 & 97.5 & 1 & 2.5 \\
\hline - Skin care & 32 & $18.2 \pm 2.8$ & 10 & 25.0 & 30 & 75.0 \\
\hline - Diaper care & 34 & $26.1 \pm 2$ & 39 & 97.5 & 1 & 2.5 \\
\hline - Bottle feeding & 30 & $21.6 \pm 2.1$ & 34 & 85.0 & 6 & 15.0 \\
\hline - Gavage feeding & 42 & $30.8 \pm 2$ & 39 & 97.5 & 1 & 2.5 \\
\hline \multicolumn{1}{|c|}{ Total Practice } & $\mathbf{3 0 8}$ & $\mathbf{2 2 3 . 9 \pm 1 4 . 3}$ & $\mathbf{3 8}$ & $\mathbf{9 5 . 0}$ & $\mathbf{2}$ & $\mathbf{5 . 0}$ \\
\hline
\end{tabular}

Table (3): Relation between total scores of practices and personal characteristics of the studied nurse's caring for jaundiced neonates $(n=40)$.

\begin{tabular}{|c|c|c|c|c|c|}
\hline \multirow{3}{*}{ Personal characteristics } & \multicolumn{5}{|c|}{ Total score of practices } \\
\hline & \multicolumn{2}{|c|}{$\begin{array}{l}\text { Satisfactory } \\
\quad(\mathbf{n}=\mathbf{3 8})\end{array}$} & \multicolumn{2}{|c|}{$\begin{array}{c}\text { Unsatisfactory } \\
(\mathrm{n}=2)\end{array}$} & \multirow[t]{2}{*}{ P. value } \\
\hline & No. & $\%$ & No. & $\%$ & \\
\hline \multicolumn{6}{|l|}{ Age / years } \\
\hline - $20-<30$ yrs. & 29 & 76.3 & 2 & 100.0 & \multirow{3}{*}{0.737} \\
\hline - $30-<40$ yrs. & 6 & 15.8 & 0 & 0.0 & \\
\hline - $>40$ yrs. & 3 & 7.9 & 0 & 0.0 & \\
\hline \multicolumn{6}{|l|}{ Level of education: } \\
\hline - Nursing diploma. & 33 & 86.8 & 2 & 100.0 & \multirow{2}{*}{0.573} \\
\hline - Technical institute of nursing. & 5 & 13.2 & 0 & 0.0 & \\
\hline \multicolumn{6}{|l|}{ Marital status: } \\
\hline - Married. & 31 & 81.6 & 2 & 100.0 & \multirow{2}{*}{0.873} \\
\hline - Single. & 7 & 18.4 & 0 & 0.0 & \\
\hline
\end{tabular}

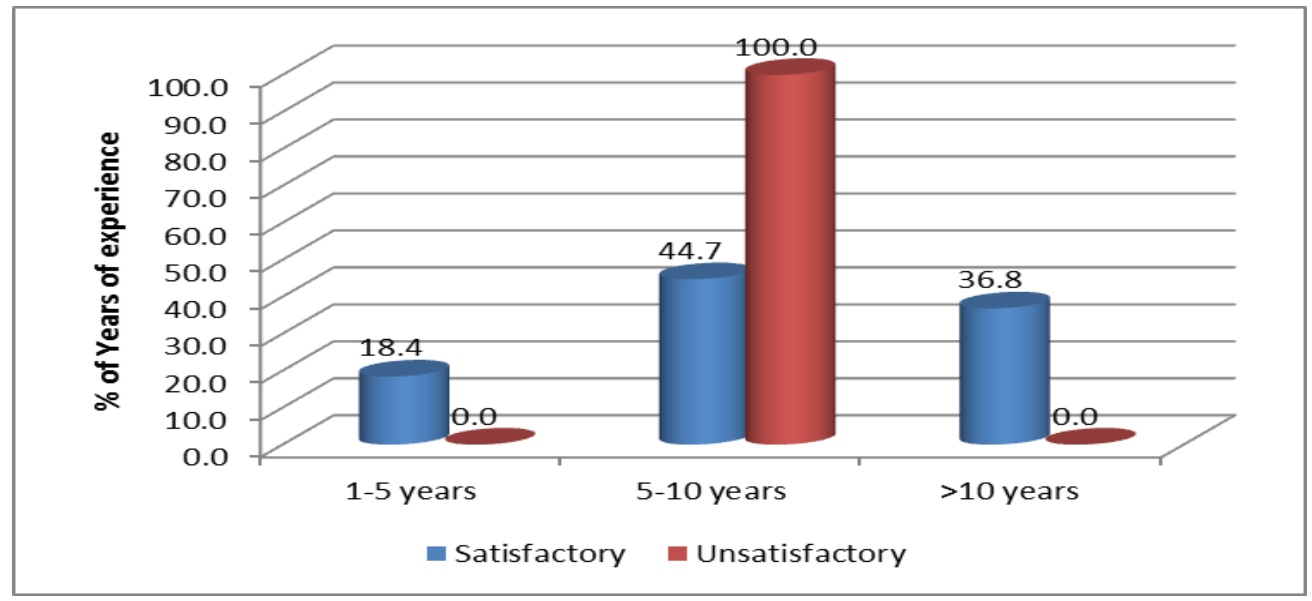

Figure (3): Relation between the studied nurses' score of practice and their years of experience. 


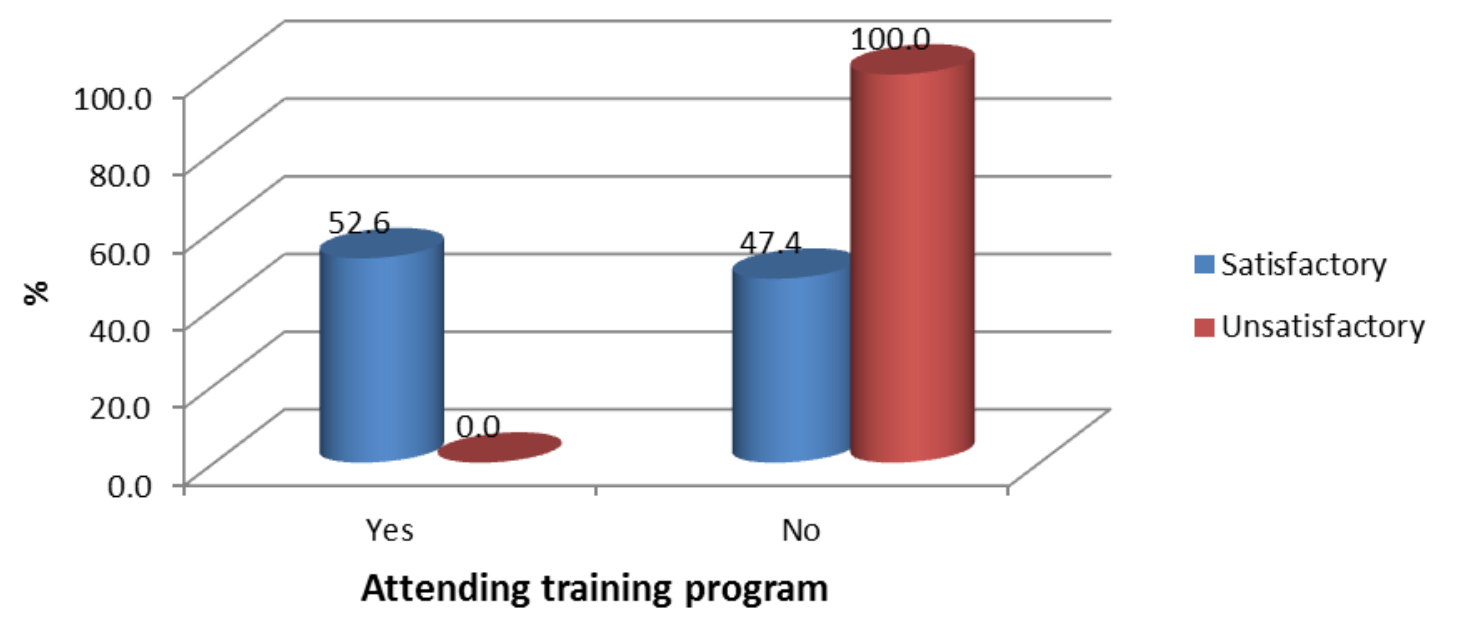

Figure (4): Relation between the studied nurses' score of practice and their attendance of training courses.

Table (4) pesonal and clinical charactaristics of the studied jaundice neonates $(n=140)$

\begin{tabular}{|c|c|c|}
\hline Neonates charactaristics & $\mathbf{n}$ & $\%$ \\
\hline \multicolumn{3}{|l|}{ Gender: } \\
\hline Male & 77 & 55 \\
\hline Female & 63 & 45 \\
\hline \multicolumn{3}{|l|}{ Blood group: } \\
\hline - $\mathrm{A}$ & 48 & 34.3 \\
\hline - $\mathrm{B}$ & 65 & 46.4 \\
\hline - $\mathrm{O}$ & 19 & 13.6 \\
\hline - $\mathrm{AB}$ & 8 & 5.7 \\
\hline \multicolumn{3}{|l|}{ Rh: } \\
\hline - $\quad$ Positive & 133 & 95 \\
\hline - Negative & 7 & 5 \\
\hline \multicolumn{3}{|l|}{ Types of feeding: } \\
\hline - Breastfeeding only & 5 & 3.6 \\
\hline - $\quad$ Artificial feeding only & 49 & 35 \\
\hline - $\quad$ Supplementary feeding & 86 & 61.4 \\
\hline
\end{tabular}

Table (1): Shows personal characteristics of the studied nurses. It was found that more than three quarters $(77.5 \%)$ of them were in the age group from 20 years to less than 30 years and about less than fifth of them (15\%) were in the age group from 30 to less than 40 years and $(7.5 \%)$ were in the age group 40 years and more, While more than three quarters $(87.5 \%)$ were graduated from secondary school of nursing and only (12.5\%) of them were graduated from technical institute of nursing. According to marital status, it was found that more than three quarters $(82.5 \%)$ of them were married .
Figure (1): Shows distribution of the studied nurses according to their attendance of training programs . It was found that half $(50 \%)$ of them attended training courses and half $(50 \%)$ of them did not attend training courses about neonatal care .

Figure (2): Illustrate distribution of the studied nurses according to their years of experience. It was noticed that less than half $(47.5 \%)$ of them had experience from 5 to 10 years and more than one third of them (35\%) had experience more than 10 years while only (17.5\%) had experience less than 5 years. 
Table (2): Presents mean score of the studied nurses practice regarding jaundiced neonates in each procedure. It was found that all of the studied nurses $(100 \%)$ had satisfactory level of practice related to body weighing, and one quarter $(25 \%)$ of them had satisfactory level of practice related to skin care, while only $(2.5 \%)$ had unsatisfactory level of eye care, diaper care and gavage feeding.

Table (3): Illustrates relation between total scores of practices and personal characteristics of the studied nurse's caring for jaundiced neonates. There were no statistical significant difference between total score of practice and their marital status, age, and educational level.

Figure (3): Presents relation between the studied nurses' score of practice and their years of experience. There were no statistical significant difference between nurses' score of practice and their years of experience.

Figure (4): Presents relation between the studied nurses score of practice and their attendance of training courses. There were no statistical significant difference between nurses' score of practice and their attendance of training courses.

Table (4): Illustrates pesonal and clinical charactaristics of the studied jaundiced neonates. It was found that more than half $(55 \%)$ of them were male gender, about one third $(34.3 \%)$ of them were A blood group, it noticed that the majority $(95 \%)$ were positive $\mathrm{Rh}$ and only (3.6\%) of them had breast feeding only.

\section{Discussion}

Nurses play a vital role in coordinating communication among all members of the newborn's care team, including physicians, laboratory personnel and parents. Also, one of the most integral nursing care for neonatal hyperbilirubeinemia is the care during phototherapy. Proper nursing care enhances the effectiveness of phototherapy and minimizes its associated complications. Providing care to neonates with hyperbilirubinemia is a condition that requires safe knowledge and skills to achieve optimal health outcomes. Consequently, neonatal nurses should acquire advanced up to date knowledge and practices to save newborns' life (Hockenberry et al., 2011). Regarding personal characteristics of the studied nurses, the result of the

current study showed that more than three quarters of the nurses age was less than thirty years, this result was similar to a study by Joseph, (2015) who carried study entitled assessment of knowledge on causes and care of neonatal jaundice at the Nigerian primary and secondary health institutions who found that the age group of nurses were between twenty to thirty years.
The current study revealed that the majority of the studied nurses had secondary school nursing diploma, this result was in accordance with Mahmoud \& Hani, (2017) in their study about assessment of nurse's knowledge and practice working in district hospitals at Minia governorate about neonatal hyperbilirubinemia. This may be due to the fact that nursing secondary school provides the community with large number of diploma nurses graduates than other agencies such as faculties of nursing and technical institutes of nursing.

Regarding marital status of the studied nurses, the findings of the current

study showed that, the majority of the studied nurses were married, these findings were in accordance with Ashour et al., (2016) about effect of a designed nursing care protocol on clinical outcomes of neonates with hyperbilirubinemia who found that the majority of the nurses were married and from rural area.

The current studys results showed that half of the studied nurses attended training program, this finding supported by (Joseph, 2015). who found that the majority of nurses attended training program about neonatal jaundice. The responsible personnel of NICU made frequent training program to ensure that their nurses are aware of all up to date knowledge and practice.

Regarding the years of experiences of the studied nurses, the finding of the current study showed that less than half of them had experience from five to ten years. This result disagreed with Mahmoud \& Hani, (2017) who found that more than two thirds of the nurses had experience less than five years.

Regarding nurses' practice related to care of jaundiced neonates receiving phototherapy, the majority of nurses had satisfactory level of practice. This finding was in agreement with Piri et al., (2015) in their study about auditing phototherapy-related nursing care in neonatal general and intensive care units.

Regarding hand washing, findings of the present study revealed that, more than two thirds of the studied nurses had unsatisfactory level of practice related to hand washing, this result disagree with Abd El Fattah et al., (2012) in their study about quality of nurses' performance regarding parenteral nutrition at neonatal intensive care units who found that more than half of nurses had a good level of practice regarding hand washing. This might be due to hand washing was followed routinely in the most nursing procedures and the nurses had overloaded of work.

Regarding nurses' practice related to measuring weight, all the studied nurses had satisfactory level of 
measuring weight and this finding was in agreement with Guadan et al., (2011). in their study about improving the knowledge and practice on early detection of neonatal jaundice by nurses in Kuching District who reached to the same finding.

The importance of vital signs cannot be ignored as it is a basic nursing activity in the neonatal assessment which should precede nursing care planning and implementation. On assessing nurses' practice regarding the measurement of vital signs, the current study clarified that the majority of the studied nurses had a satisfactory level of practice in measuring axillary temperature and counting respiration . This result agrees with Ahmed, (2014). Who found that all nurses had a good level of practice regarding measuring vital signs. This may be due to that measuring axillary temperature is routinely performed by nurses in NICU. Usually counting heart rate was performed by the physician according to the hospital policy.

Regarding the nurses' practice related to cord care, eye care and diaper care, the current study presents that the majority of the studied nurses had a satisfactory level of practice; this result was similar to Abd El Fattah et al., (2012). Who found that more than half of the studied nurses had a good level of practice regarding to cord care, eye care and diaper care.

In the present study, nurses had satisfactory level of practice regarding bottle and gavage feeding. These findings were similar to that of Mahmoud et al., (2011). in their study about assessment of nursing care provided to premature neonates at neonatal intensive care unit at zagazig university children hospital who found that nurses had satisfactory level of practice regarding bottle and gavage feeding.

The current study's result showed more than half of the studied jaundice neonates were male gender these findings were in agreement with (Raid, 2012). in his study about effectivenesss of $360^{\circ}$ intensive phototherapy versus conventional phototherapy for neonatal hyperbilirubinemia who reached to the same findings.

The present study revealed that there were no statistically significant relationship between nurses' level of practice and their personal characteristics these findings disagree with the finding of the study done by Abd El-Galil, (2009). who found that, there was statistical significant relation between nurses' practice and experiences and was in agreement with Mohamed, (2010). who found that there was no statistical significant relationship between nurses' practice and their level of education.

\section{Conclusion}

Based on the results of the present study, it can be concluded that there had no statistical significant relation between nurses level of practice, and their marital status, residence, age, years of experience and educational level.

\section{Recommendations}

Based on the results of the current study, the

following recommendations are suggested:

1. Periodical educational programs for nurses working at NICU are mandatory, for the purpose of raising and updating the knowledge and practice of nurses regarding hyperbilirubinemia.

2. Films and audiovisual conferences about practical procedures should be done for nurses during these programs.

3. Providing nurses with procedure manual hand books containing all necessary information about nursing procedures related to quality of nursing care for neonates with hyperbilirubinemia will be beneficial.

\section{References}

1. Abd El Galil N., (2009): Monitoring Quality of Nursing Care in Neonatal Care Units at Hospitals, affiliated to Ministry of Health, Dakahlia Governorate, Unpublished, Master Thesis, Faculty of Nursing, Mansoura University, Egypt, Pp, 65-86.

2. Abdel-Fattah N., Shafik F., \& Mostafa S., (2012): Quality of Nurses' Performance Regarding Parenteral Nutrition at Neonatal Intensive Care Units. Egyptian journal of health care, 9(2): 116-28.

3. Ahmed R., (2014): Quality of nursing care provided for neonates with tracheoesophageal fistula, journal of education and practice, Vol (5), No (3), Pp: 186-99

4. American Academy of Paediatrics (2011): Clinical practice guideline. Management of hyperbilirubinaemia in the newborn infant 35 or more weeks gestation. Paediatrics; 114,297-316.

5. Ashor G., Khalifa M., \& Fady M., (2016): Effect of a designed nursing care protocol on clinical outcomes of neonates with hyperbilirubinemia. International Journal of Novel Research in Healthcare and Nursing, 3(3): 62-76.

6. Cremer R., Perryman P., \& Richards D., (1958): Influence of light on the hyperbilirubunaemia of infants. Lancet; 1: 10947 . 
7. Edris A., Ghany E., Razek A., \& Zahran A., (2014): The role of intensive phototherapy in decreasing the need for exchange transfusion in neonatal jaundice. J Pak Med Assoc 1: 5-8.

8. Gadun A., Juliana H., \& Baun L., (2011): Improving the Knowledge and Practice On Early Detection of Neonatal Jaundice by Nurses in Kuching District. International Journal of Public Health Research Special Issues, 92-99.

9. Gurley, E., Halder, A., Streatfield, P., Sazzad, H., Huda, T., Hossain, M., \& Luby, S., (2012): Estimating the burden of maternal and neonatal deaths associated with jaundice in Bangladesh American Journal Of Public Health,102(12), 2248-2254.

10. Henny-Harry, C., \& Trotman, H., (2012): Epidemiology of neonatal jaundice at the University Hospital of the West Indies. The West Indian Medical Journal, 61(1), 37-42.

11. Hockenberry M., Wilson D., \& Marilyn J., (2011): Nursing Care of Infants and Children, $9^{\text {th }}$ ed., Canada, Mosby Company, Chapter 1: Perspective of Pediatric Nursing, Pp:16.

12. Joseph O., (2015): Assessment of knowledge on causes and care of neonatal jaundice at the Nigerian primary and secondary health institutions . Int J Res Med Sci., 3(10):2605-2612

13. Kliegman R., Behrman RE, Geme J., Stanton B., \& Schornf, (2011): Nelson text book of pediatrics, Saunders EISEVIER, USA $19^{\text {th }}$ ed chap 96 pp. 610-11

14. Macqueen, S., Bruce, E., \& Gibson, F., (2012): The Great Ormond Street Manual of Children's Nursing Practice. Wiley Blackwell: Chichester.

15. Mahmoud B., Mohammed A., \& El-Awady S., (2011): Assessment of Nursing Care Provided to Premature Neonates at Neonatal Intensive Care Unit at Zagazig University Children Hospital. Zagazig Nursing Journal, 7(2) 2011.

16. Mahmoud S., \& Hani M., (2017): Assessment of Nurse's Knowledge and Practice Working in District Hospitals at Minia Governorate about Neonatal Hyperbilirubinemia. Iosrjournals, 6(2): 9-16.

17. Maisels M., \& Kring E., (2006): The contribution of hemolysis to early jaundice in normal newborns. Pediatrics 118,276-9.

18. Maisels, M., Clune, S., Coleman, K., Gendelman, B., Kendall, A., McManus, S., \& Smyth, M., (2014): The natural history of Jaundice in Predominantly Breastfed Infants. Pediatrics, 134(2): 340-350.

19. Mohamed S., (2010): Quality of Nursing Care for Neonates with Respiratory Distress Syndrome, Pediatric Department, Unpublished,
Master Thesis ,Faculty of Nursing, Benha University, Egypt, Pp: 45- 64.

20. Norman M., Åberg K., Holmsten K., Weibel V., \& Ekéus C., (2015): Predicting Nonhemolytic Neonatal Hyperbili-rubinemia. Pediatrics.; 136(6):1087-94.

21. Olusanya B., Osibanjo F., Mabogunje C., Slusher T., \& Olowe S., (2016): The burden and management of neonatal jaundice in Nigeria: a scoping review of the Pediatr.; 23(3):241-8.

22. Piri F., Manijeh N., \& Azam S., (2015): Auditing phototherapy-related nursing care in neonatal general and intensive care units. Iran $\mathbf{J}$ Crit Care Nurs., 8(3):167-172.

23. practice guidelines with AGREE II: The example of neonatal jaundice. Arch

24. Raid M., (2012): Effectiveness of 360。 Intensive Phototherapy versus Conventional Phototherapy for Neonatal Hyperbilirubinemia. Kufa Med. Journal VOL.15.No.1, Pp 204.

25. Renesme L., Bedu A., Tourneux P., \& Truffert P., (2016): How to assess clinical practice guidelines with AGREE II: The example of neonatal jaundice. Arch Pediatr.; 23(3):241-8.

26. Skinner S., (2010): Neonatal Care. In Glasper A, Aylott M. and Battrick C. Developing Practical Skills for Nursing Children and Young People. Hodder Arnold Publishers Ltd., London, 508-512.

27. Stokowski, L., (2011): Foundations in Newborn Care: Fundamentals of Phototherapy for Neonatal Jaundice. Advances in Neonatal Care 11 (5)

28. Wong's (2015): Nursing care of infant and children. Mosby, Inc., an affiliate of Elsevier Inc, Canda 10 th ed chap 8, Pp 313-. 